\title{
A look at EIPD Strategic Initiative projects
}

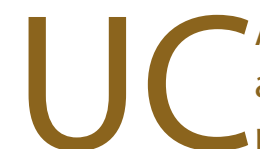

ANR's five strategic initiatives seek new ways of partnering within and outside the university to tackle emerging issues in California. As part of this strategic vision, the Division annually funds research and extension projects in and across all initiatives. Four recent and ongoing studies in the Endemic and Invasive Pests and Diseases Strategic Initiative are profiled here.

\section{Thousand cankers disease}

$\neg$ housand cankers disease "is a rapidly emerging 1 invasive threat to walnut orchards in California," says Richard Bostock, plant pathologist at UC Davis and a lead researcher on a 3-year study of the disease. "Only in a few places in the state have English walnut trees died due solely to this disease," he says, "but it's on its way to becoming endemic in all the walnut-growing areas, and we are still not sure where this is going to go."

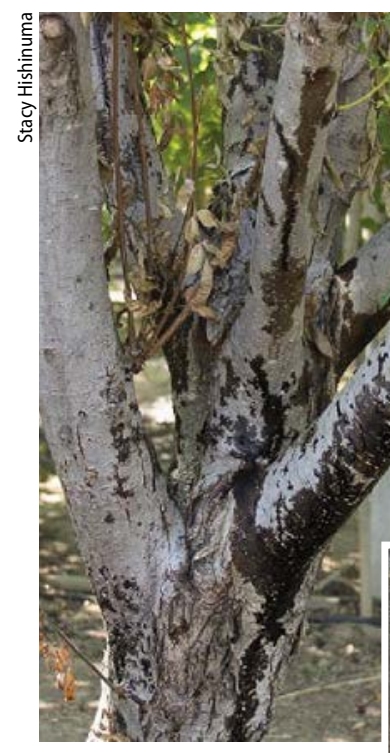

Above, a heavily infected Southern California black walnut (Juglans californica) showing sapstaining of the bark and dieback. Inset, a canker underneath the outer bark of a Paradox hybrid walnut showing necrosis around walnut twig beetle tunnels.
The fungal pathogen, Geosmithia morbida, was new to science when it was found in California in 2008 in Northern California black walnut trees growing in Davis. Its vector, the walnut twig beetle (WTB), has been known in California since 1959. The male beetles attack a tree first, releasing a pheromone that attracts thousands of beetles to the phloem tissue of the tree's trunk and large branches, where they tunnel, feed and produce offspring. Spores of the pathogen are carried on the vec-

tor's body and infect the host tissue; the cankers produced by the pathogen coalesce and can girdle a trunk or branch, and in severe cases can cause decline and death of the tree.

The study, reaching completion now and codirected by Steven Seybold, a USDA Forest Service entomologist, has assessed the distribution of thousand cankers disease in the state's walnut-growing areas, differences among walnut (Juglans) species in their reaction to the pathogen and attractiveness to the beetle, the genetic diversity of the fungus and the biology of the beetle. The disease appears to be present in all areas; in some orchards, there is a very low incidence of the disease, while in others, as many as $90 \%$ of the trees have WTB attacks and cankers.
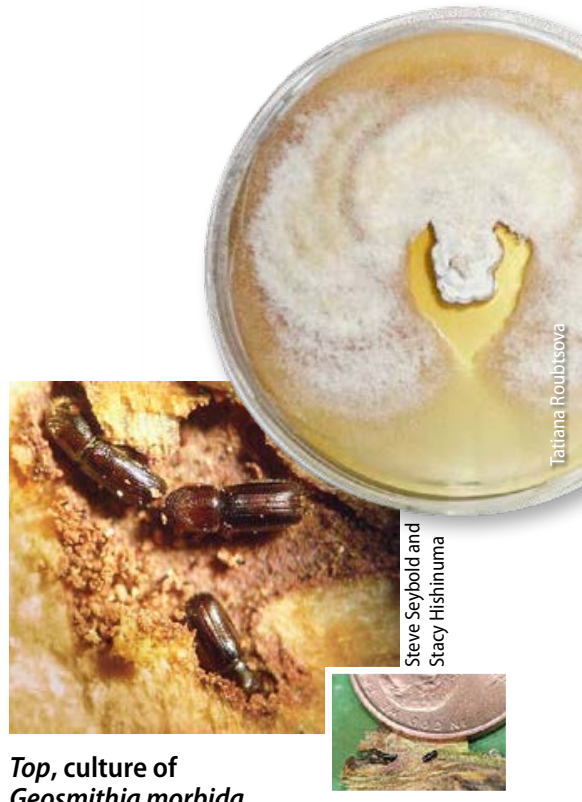

Geosmithia morbida,

the fungal pathogen that causes thousand cankers disease. Middle, close-up of walnut twig beetles tunneling in the bark of an infected tree. Bottom, actual size of the beetle in relation to a penny.

Thousand cankers disease has decimated eastern black walnut, Juglans nigra, in landscape and urban plantings in some Western states and parts of Colorado, where, in 2008, the association of the beetle and fungal pathogen in the disease was first discovered and reported by researchers at Colorado State University. In 2010, the disease was reported on eastern black walnut in Tennessee and subsequently in other Eastern states within the native range of this species. In California, the research team has documented the disease in the Southern California black walnut, Juglans californica, in English walnut, Juglans regia, which is the commercial orchard species, and in Northern California black walnut, Juglans hindsii, which is used as a rootstock for J. regia, and also in Paradox rootstocks. "About 70\% of commercial trees are on Paradox," says Bostock, and the study has discovered that "Paradox is highly susceptible and is very attractive to the beetles." Investigating the population structure of the fungus in different geographic regions in the United States, other researchers have reported "a great deal of diversity in the fungal population in Arizona, California and New Mexico," says Bostock, "and their findings suggest that these states could be the source of the thousand cankers disease epidemic."

The susceptibility of Paradox and the destruction the disease has caused in eastern black walnut are cause for concern, but "we are not raising a lot of 
and directions on what to do if an ACP is found: Act fast! Call the California Department of Food and Agriculture (CDFA) hotline, 1-800-491-1899, to report the finding; if it's a finding in a new area, CDFA provides eradication treatment, but if ACP is already established in the area, the homeowner is directed to manage the psyllids on their own.

Economist Karen Jetter (Agricultural Issues Center, UC Davis) has created tables on the website showing the costs of various treatments for both homeowners and growers. A cost calculator helps conventional and organic growers compare the cost per acre of various chemical options. "We are in the process of surveying growers in various regions of the state to determine what chemical choices they have made over the last 4 years, so that we can provide an analysis of costs by region," says Grafton-Cardwell.

For outreach, the project team is providing training to the general public through Master Gardeners

\section{Bovine respiratory disease}

Rovine respiratory disease is one of the leading 3 causes of death in preweaned dairy heifers in the United States. To help dairy farmers diagnose and control the disease, a new scoring system to assess the respiratory health of preweaned dairy calves has been developed in research led by Sharif Aly at the Veterinary Medicine Teaching and Research Center, UC Davis. Called the California Bovine Respiratory Disease Scoring System, it is composed of six questions requiring only yes/no answers and can be easily used on-farm by owners, veterinarians and farmworkers.

The 4-year study began in 2012. The goals of the research were to collect data on current management practices and to develop a simple, low-cost clinical diagnostic scoring system that could be used on farms to identify clinical signs early, avoid unnecessary animal deaths and misuse of antimicrobials, and track the health of calves over time.

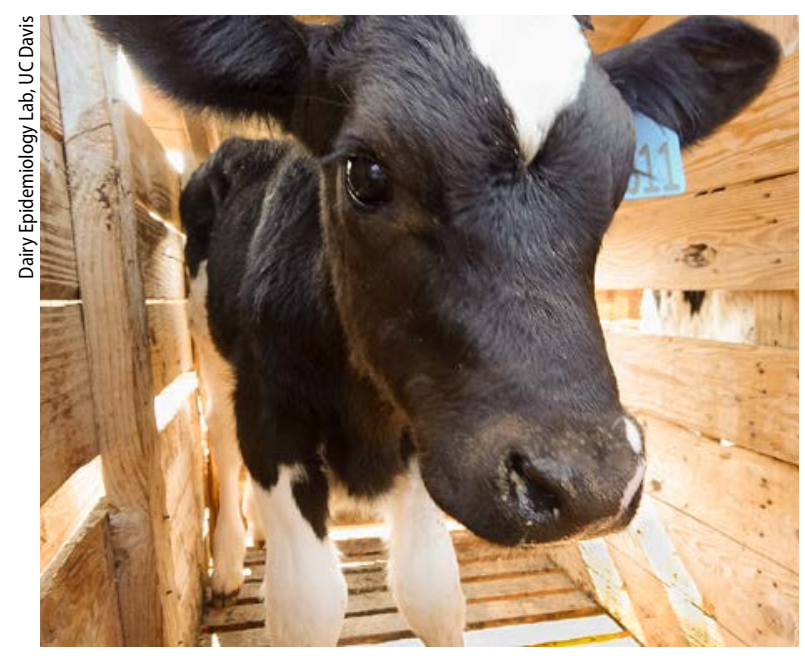

and retail nurseries. The team works with local grower task forces in citrus areas infested with ACP, such as the Imperial Valley, Ventura County and the San Joaquin Valley, helping them to develop ACP management strategies. The website is used as an educational tool during these meetings. GraftonCardwell communicates a clear message that insecticide spraying to slow the spread of ACP and keep numbers low is critical for preventing psyllids from finding diseased trees and helps to buy time for researchers to develop a cure for the disease.

Other members of the project team are Matthew Daugherty (Entomology, UC Riverside) and Robert Johnson (UC ANR Informatics and GIS Program).

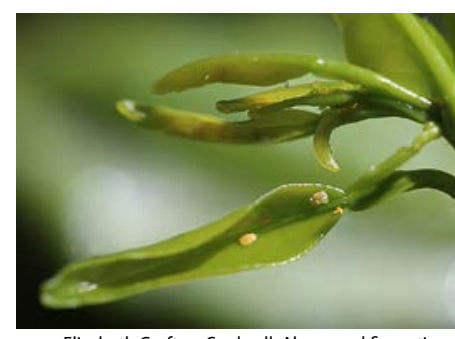

Elizabeth Grafton-Cardwell: Above and fingertip

A survey questionnaire was sent to 1,450 dairies in 2012 with questions on calf management practices.

The data was statistically analyzed to identify the most important factors that may be related to the risk of bovine respiratory disease. Then, a model-based scoring system was developed for six clinical signs: eye discharge (2), nasal discharge (4), ear droop or head tilt (5), spontaneous cough (2), rapid or difficult breathing compared to other calves (2) and temperature at or above $102.5^{\circ} \mathrm{F}(2)$. A score of 5 or higher suggests a calf may have respiratory disease.

The scoring system has been validated in a study of 500 calves on three dairy farms and two calf ranches in California; results are expected to be published in 2015. One of the advantages of the California scoring system compared to the Wisconsin scoring system, developed in 2008, is that it requires less calf handling and allows easier assessment of clinical signs. A recent study compared the diagnoses of both systems and showed excellent agreement beyond chance.

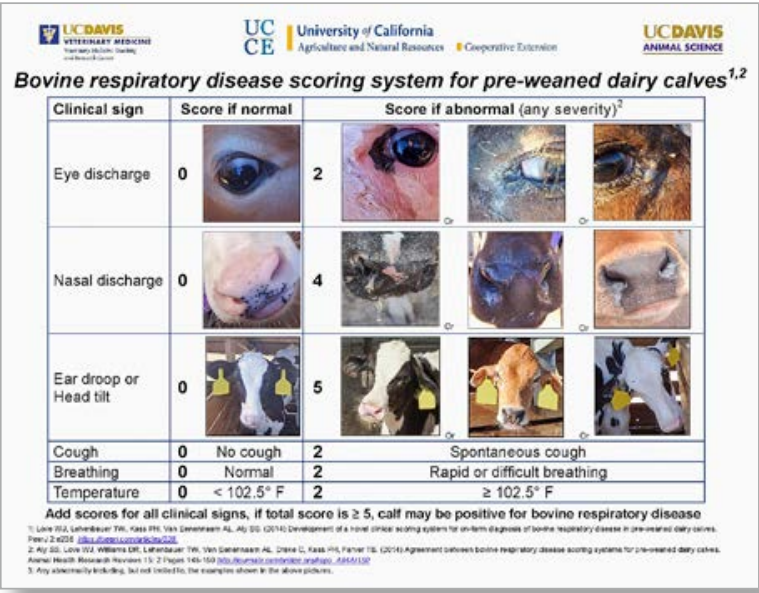

Aly stresses how easy it is to use the California scoring system. "We've had very good feedback from dairies," he says. "Assessing each clinical sign as present or absent takes the guesswork out of diagnosis. In addition, the scores and cut-off for case status are

The California Bovine

Respiratory Disease Scoring System allows owners, vets and farmworkers to easily diagnose respiratory disease in preweaned calves. 
model based." Because it is so simple, the scoring system can be used daily, for example, on sick calves to confirm respiratory disease status prior to treatment.

The team's current research is focused on developing a risk assessment tool that incorporates the new scoring system and also a questionnaire, based on the statewide survey, that points to risk mitigation strategies. The questionnaire can be completed by a calf raiser and the herd veterinarian to form a disease control plan. The scoring system can be used to monitor the prevalence of respiratory disease in calves once control measures are implemented. The risk assessment tool will be used to monitor 5,000 calves on different dairies for the risk of bovine respiratory disease in collaboration with dairy farm advisors and UC Cooperative Extension specialists.

The research team also includes Terry Lehenbauer and Alison Van Eenennaam (Animal Science, UC Davis), Randall Anderson (CDFA), Alejandro Castillo (UCCE Merced County), Carol Collar (UCCE Kings County), Christiana Drake (Statistics, UC Davis), Jennifer Heguy (UCCE Stanislaus County), Lindsey Hulbert (Animal Science, UC Davis), Betsy Karle (UCCE Glenn County), Frank Mitloehner (Animal Science, UC Davis), Nyles Peterson (UCCE San Bernadino County) and Noelia Silvadel-Rio (UCCE Tulare County).

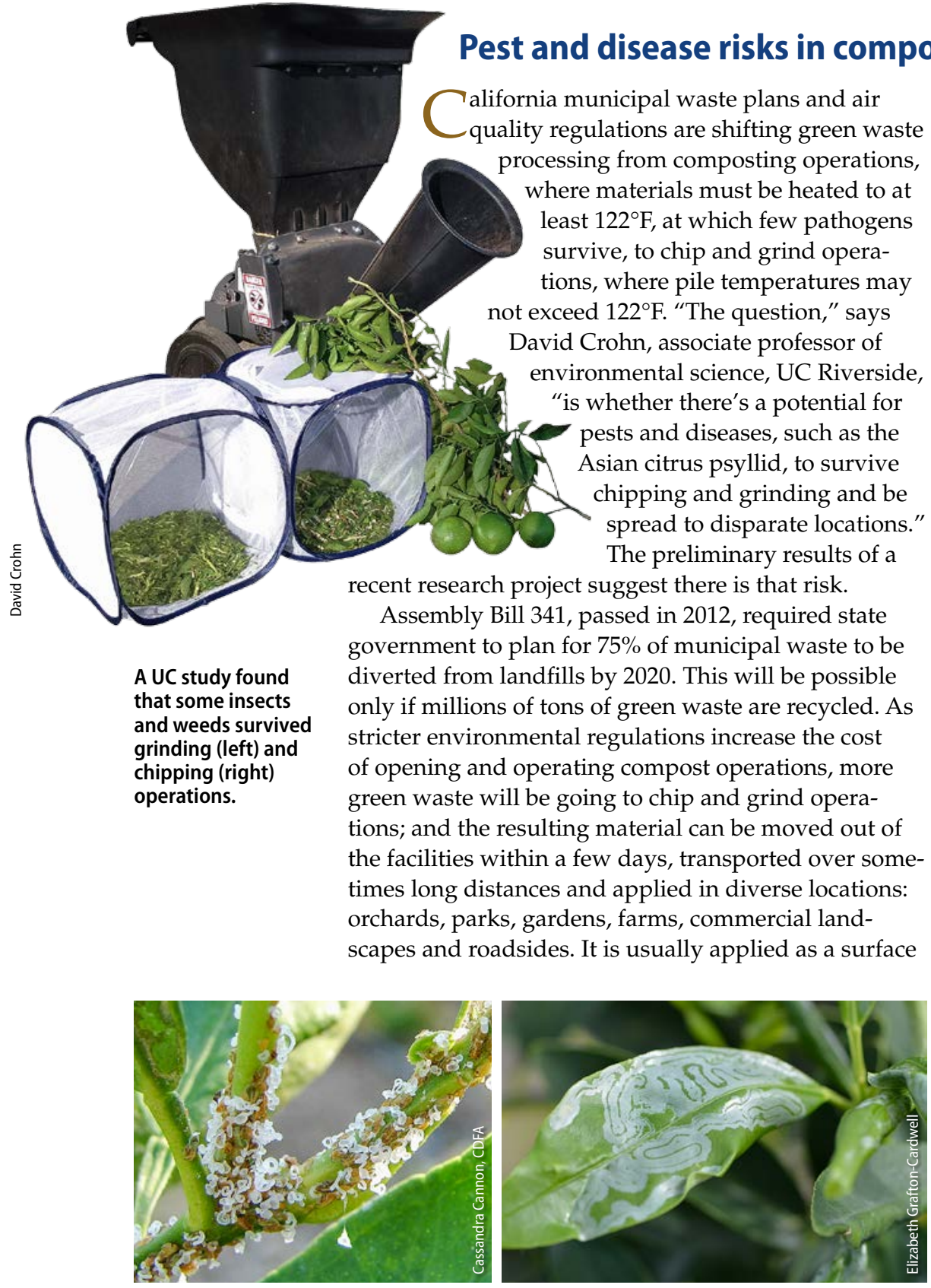

Asian citrus psyllid nymphs (left) and citrus leafminer damage (right).

mulch, which can allow a pest or disease to be easily spread by wind, water or wildlife.

Crohn, who is a waste management specialist, and a team of other UC specialists, farm advisors and graduate students set up simulated composting and chip and grind environments and compared the survival rates of Asian citrus psyllid, citrus leafminer larvae, tobacco mosaic virus, fusarium in palms, bermudagrass, nutsedge, and clover and tomato seeds. In each environment, pest and disease samples were either placed in mesh bags or in envelopes in the green waste material, and either the material was heated to $122^{\circ} \mathrm{F}$ (i.e., composted) or kept at $77^{\circ} \mathrm{F}$, ambient temperature, for 3 days.

"The results were a mix," says Crohn. "Citrus leafminer was controlled by chipping and grinding; Asian citrus psyllid, though, had some survival in chipping and grinding but was controlled by composting." In terms of the weeds, chipping and grinding "was effective at inactivating nutsedge, but clover and tomato seed survived it just fine."

Crohn stresses this was a small study, and it is impossible to simulate the variety of conditions in commercial green waste operations. But in terms of the risks of invasive pests and diseases being spread more easily and rapidly through chipping and grinding, the preliminary results, he says, "suggest there's reason for concern."

The next step of the research is to analyze the economic impact of the state regulatory policies on composting and chip and grind operations. Chip and grind operations are exempt from costly new rules to protect air and water quality; composting facilities are not exempt.

The project team also includes Matthew Daugherty (Entomology, UC Riverside), James Downer and Ben Faber (UCCE Ventura County), Deborah Matthews (Plant Pathology, UC Riverside) and Steven Swain (UCCE Marin County). CA

- Hazel White 